\title{
Um estudo sobre a invisibilização de fontes sobre o coronavírus em O Grande Debate
}

Juliana Costa ${ }^{1}$

Kênia Maia²

\section{Resumo}

O artigo se propõe a refletir sobre a ocorrência de invisibilização de fontes jornalísticas acionadas por comentaristas participantes do quadro $O$ Grande Debate, da CNN Brasil. Reflete sobre funções das fontes jornalísticas e seu papel em espaços de opinião no jornalismo, além de tensionar os efeitos da ocorrência de sua invisibilização para a credibilidade jornalística. Ao examinar dez edições do quadro voltadas para a exploração de temas relacionados à pandemia provocada pelo novo coronavírus, observa divisões temáticas e confronta os tipos de fontes acionadas com o tema de cada quadro. Ao final, o trabalho aponta a ocorrência de deslocamento de credibilidade de fontes.

Palavras-chave: Fontes jornalísticas. Invisibilização. Coronavírus.

\section{A study about the invisibility of sources on coronavirus in O Grande Debate}

\section{Abstract}

The article aims to reflect on the occurrence of the invisibility of journalistic sources produced by commentators who participate of the O Grande Debate, a CNN Brazil TV show. It reflects on the functions of journalistic sources and their role in spaces of opinion, in addition to tensioning the effects of the occurrence of their invisibility for journalistic credibility. When examining 10 editions of the TV show aimed at exploring themes related to the pandemic caused by the new coronavirus, it observes a thematic division and confronts the types of sources used with the theme of each

\footnotetext{
1 Doutoranda no Programa de Pós-Graduação em Estudos da Mídia, da UFRN. Mestra em Comunicação pela UFPE. Jornalista do IFPE. E-mail: juliana.costa.jor@gmail.com

2 Doutora em Ciência da Informação e da Comunicação pela Universidade Paul Verlaine - Metz. Professora do Departamento de Comunicação da UFRN e dos Programas de PósGraduação em Estudos da Mídia e em Gestão da Informação e do Conhecimento, da UFRN. E-mail: kbiamaia@gmail.com
} 
program. At the end, the paper points to the occurrence of a shift in credibility of sources.

Keywords: Journalistic sources. Invisibility. Coronavirus.

\section{Introdução}

O ano de 2020 marcou o início das transmissões da CNN Brasil, canal de programação integralmente jornalística e, restrito àqueles que contam com o serviço de operadoras de televisão por assinatura, multiplataforma (tem página no Facebook, no Twitter, um canal no YouTube e um site oficial). Entre suas iniciativas de maior popularidade está o quadro O Grande Debate, que propõe o embate de posicionamentos distintos de comentaristas sobre assuntos abordados no noticiário.

Ao mesmo tempo, a pandemia provocada pelo novo coronavírus ganhou cada vez mais espaço na mídia: entre espaços jornalísticos e/ou de entretenimento, o tema obteve projeção e foi tratado sob diferentes aspectos. A cobertura da ocorrência de casos de infecção e morte, aspectos socioeconômicos associados às consequências da pandemia, discussões sobre pesquisas para o desenvolvimento de uma vacina e mesmo os reflexos políticos sobre o gerenciamento da crise sanitária em território nacional e internacional ocuparam a pauta de diferentes veículos de comunicação.

O cenário reforçou a importância das fontes especializadas para a construção de notícias ou reportagens que pretendessem abordar o novo coronavírus, a Covid-19, ou mesmo as consequências socioeconômicas da pandemia. Nossa inquietação, todavia, dirigiu-se para os espaços jornalísticos voltados à opinião. Era necessário perguntar se, nestes casos, as fontes estavam visíveis nas opiniões emitidas em espaços jornalísticos quando da abordagem de tais assuntos. Nossa hipótese é de que as fontes passam por um processo de invisibilização, de modo que há um deslocamento da credibilidade mais associado à exposição midiática de quem opina do que à sua especialidade ou à especialidade de suas fontes.

Desse modo, nosso objetivo no presente artigo é verificar a ocorrência de invisibilização de fontes na abordagem do novo coronavírus e suas consequências em edições do quadro O Grande Debate. Para isso, estabelecemos uma discussão sobre funções e perspectivas das fontes jornalísticas e, em seguida, refletimos sobre o papel 
destas na exposição de opinião em espaços jornalísticos. A partir daí, tensionamos a possibilidade da invisibilização sob a perspectiva dos efeitos na credibilidade. Para alcançarmos nosso objetivo, observamos dez edições do quadro em questão, apontando o perfil dos participantes, expondo as divisões temáticas e os tipos de fontes acionadas.

\section{Fontes: função e perspectivas}

Essenciais na construção do produto jornalístico e objeto de reflexão sob diferentes perspectivas, as fontes são entendidas como um caminho para a obtenção ou confirmação de informações - que, por sua vez, darão corpo à notícia ou à reportagem. Deste modo, abraçamos a perspectiva de Alsina (2009), entendendo a fonte jornalística como estando essencialmente ligada à condição de existência do produto jornalístico. Parte-se, enfim, do princípio de que a impossibilidade de ubiquidade do jornalista (PENA, 2012) determina sua dependência de fontes capazes de indicar ou mesmo determinar a informação que dará corpo ao resultado final, materializado em som, imagem ou texto, e ofertado ao público.

Pinto (2000) conceitua fonte como indivíduo (representando a si mesmo, a um grupo de pessoas, a uma organização ou a uma instância social) ou documento (preparado pelo indivíduo anteriormente, consultado ou obtido mediante pesquisa) portador de informações que elucidam, fortalecem, contestam ou aprofundam determinado assunto, sob determinada perspectiva. Para esse autor, a fonte é um elemento que reflete tramas e cenários diversos.

A percepção de fontes múltiplas e ativas (NEVEU, 2006), adaptadas ao modus operandi midiático e determinantes para a abordagem estratégica dos temas por elas pretendidos (CHAPARRO, 1994, 2014; SCHMITZ, 2011) ressalta a relevância do papel daquelas que são apontadas pelo senso comum como a origem da informação: elas podem atuar como definidores primários (HALL et al., 1993) ou mostrar-se como promotores da notícia (MOLOTCH; LESTER, 1993). Estudos que se debruçam sobre condições e/ou ações das fontes fortalecem a investigação sobre o contexto da produção da notícia.

Embora trabalhos como os de Kischinhevsky e Chagas (2017a; 2017b) indiquem a diferença entre pluralidade e diversidade das fontes acionadas, a prática da recorrência às fontes conforme suas posições em relação ao jornalista e/ou ao fato (além de seu grau de relevância no cenário considerado), tais como as demonstradas por Erbolato (2008), Lage (2005) e Chaparro (1994; 2014), reforçam a prática da recomendação de fontes 
especializadas na abordagem de assuntos que demandam perspectivas ou orientações de caráter mais técnico ou científico.

Nossa abordagem neste artigo baseia-se no papel fundamental das fontes para o produto jornalístico: mesmo passada a apuração, que entendemos ser a ocasião-clímax de atuação da fonte, esta ainda ocupa um lugar que permeia a entrevista, a notícia, a reportagem ou outro gênero, exercitando um tipo de garantia, registro-testemunhavalidador do que ali é exposto. Esse papel pode estar atrelado ao que pretende reforçar o veículo e/ou o produto jornalístico, tais como a perspectiva de um jornalismo plural e/ou ideal, permitindo que nossa reflexão seja somada àquelas que se caracterizam como de abordagem mista na seara de trabalhos sobre fontes jornalísticas (COSTA; MAIA, 2020, no prelo).

No caso de temas ligados à ciência e/ou à saúde, a prática profissional reforça a presença de fontes institucionais e/ou oficiais na imprensa (KUSCINSKY, 2002). Tal como apontado por Tuchman (1993), essas presenças servem para que a imprensa se revista de proteções de críticas e atesta o cumprimento de ritos metodológicos pelos profissionais. Além disso, a tradução de informações científicas ou técnicas para uma linguagem acessível para o público - um dos reflexos da tensão constante que permeia o jornalismo científico (MAIA; GOMES, 2006) -, entendemos, atua na construção e/ou fortalecimento da credibilidade do jornalista ou do veículo jornalístico.

\section{O papel das fontes no jornalismo opinativo}

Ao resgatar a história da evolução do jornalismo, Traquina (2012) ressaltou fenômenos relativos ao surgimento de técnicas de trabalho, estruturação de uma classe profissional e exploração da informação como matéria-prima fundamental da atividade, e isso em detrimento da manifestação da opinião do jornalista. O redirecionamento era estimulado pelos ventos da exploração comercial de seu produto mais célebre, o jornal, e pelas necessidades de adequação aos espaços que esse produto dispunha.

O momento em que a opinião passou a ser entendida como uma parte não primordial da manifestação jornalística abriu caminhos, porém, para a exploração da opinião em espaços específicos dos produtos jornalísticos. Neste sentido, as contribuições de Melo $(2003,2010)$ e Melo e Assis (2016) nos apontam uma importante perspectiva de entendimento da opinião no jornalismo. 
Isso porque tais trabalhos deixam uma fresta de compreensão fundamental para o debate: a opinião em veículos jornalísticos não era (e atualmente ainda não é) uma exclusividade de jornalistas - leitores poderiam opinar nas cartas; enquanto críticos teriam a oportunidade de fazê-lo nas resenhas, e o veículo jornalístico manifestaria sua opinião explicitamente no editorial. Entre outros exemplos que poderíamos citar aqui, também haveria a possibilidade de espaços específicos para colunistas e comentaristas (que poderiam ser jornalistas ou não) manifestarem suas análises e opiniões.

Com exceção dos espaços em que a opinião exposta é do público ou do veículo jornalístico, esta é facultada invariavelmente a especialistas que se põem a analisar um determinado tema sobre o qual têm domínio - sejam jornalistas ou não. Consideramos que tais circunstâncias abrem, assim, dois caminhos para pensarmos sobre a relação estabelecida entre fontes e a opinião exposta em espaços jornalísticos.

No primeiro, encontramos a fonte como fornecedora de dados. Neste caso, trata-se de alguém (representando a si mesmo, a outrem ou a uma organização) cuja posição e/ou conhecimentos são apontados como credenciais que o habilitam emitir análises sobre o tema em questão e que desfruta de acesso aos veículos jornalísticos para expor seus posicionamentos. No segundo, temos a fonte como ponto de partida da opinião emitida. Aqui, a fonte tanto pode ser um indivíduo (representando a si mesmo ou a outrem, bem como uma organização) ou um arquivo, que é apresentado como referência para a opinião exposta no espaço jornalístico por outro indivíduo.

Em ambos os casos, tal como nos explicam Hall et al. (1993), as fontes têm um papel essencialmente voltado para a definição das interpretações e das abordagens. No caso das fontes acionadas para a abordagem de temas ligados à ciência e/ou saúde, tais definições se mostram especialmente relevantes para a demonstração de credibilidade, potencializando o trabalho de comentaristas e colunistas.

Tal perspectiva é contemplada pela percepção de que "o sujeito deve crer que o jornalismo diz a verdade, e esta verdade deve estar justificada em seu próprio discurso" (LISBOA; BENETTI, 2015, p. 11). Para as autoras, o jornalismo se torna digno da confiança de quem o consome a partir do momento em que dá provas de que seu testemunho é verdadeiro - o que se materializa, também, na busca e citação de fontes especializadas e capazes de fornecer garantias de precisão sobre o que é tratado. Não por acaso, consideramos que tais garantias de precisão estão alinhadas ao que denominamos como fontes presumidas - aquelas cujas áreas de atuação estão necessariamente ligadas aos 
temas tratados, de modo que há a recorrência dos profissionais do jornalismo a elas. Presume-se, portanto, que fontes ligadas à construção civil serão acionadas em pautas que tratem sobre construção civil, fontes da área de educação serão acionadas para a realização de pautas voltadas para educação, e assim sucessivamente.

Ao mesmo tempo em que refletimos sobre a presença das fontes presumidas, admitimos que recorrer a fontes especializadas reforça o antagonismo entre a opinião expressa em espaços jornalísticos e as fake news - cujo entendimento, apesar da variedade de abordagens, versa invariavelmente pela falsidade de informações veiculadas (CARVALHO, 2019), bem como a perspectiva dessas "notícias falsas" como mutações dentro do jornalismo e o questionamento de autoridade das instituições (JORGE, 2017).

\section{(In)Visibilização como possibilidade}

O tema da invisibilização no jornalismo já foi abordado por autores em diferentes estudos. São exemplos desses esforços reflexivos trabalhos como os de Antunes e Góes (2015); de Pereira, Caleffi e Albertini (2019); e de Muribeca, Esteves e Brito (2019), que partiram da perspectiva da invisibilização referente a temas como questões identitárias, mulheres jornalistas e políticas públicas, respectivamente. Ao tratarem sobre a invisibilização e delinearem uma investigação a partir do produto jornalístico, esses trabalhos permitiram observar quadros e considerações sobre como a mídia se comportava ao invisibilizar atores e/ou temas.

A possibilidade de invisibilização das fontes jornalísticas, por outro lado, aponta para duas questões simultâneas: a primeira, voltada para o questionamento sobre o reflexo dessa invisibilização para a credibilidade do jornalista, do produto e/ou do veículo jornalístico; a outra, apontando para as estratégias conforme as quais a invisibilização se dá nos espaços observados. Voltamos nossa atenção sobre esses dois pontos, considerando o papel das fontes e o papel daqueles que as invocam para validarem seus discursos, sob pena de ignorarmos aspectos primordiais da discussão caso não o façamos.

No primeiro ponto, para examinarmos o reflexo da invisibilização das fontes para a credibilidade, nos concentramos em sua função e efeito. Conforme Lisboa (2012), há a credibilidade constituída, referente a quem enuncia; e a credibilidade percebida, que diz respeito àquela atribuída pelo interlocutor. 


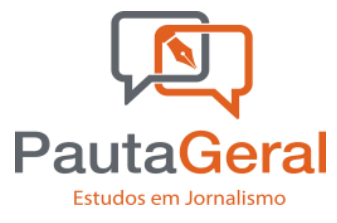

$\mathrm{Na}$ abordagem de temas relacionados à ciência e/ou saúde, as fontes especializadas estão abrigadas sob a égide da credibilidade constituída, reforçando uma posição de autoridade necessária para ocuparem determinado espaço. Por outro lado, a credibilidade percebida estaria na percepção do indivíduo que consome o jornalismo, numa consequência de tensionamentos e negociações estabelecidas entre as partes envolvidas. Deste modo, podemos considerar que:

Do ponto de vista epistêmico, o discurso jornalístico deve prover evidências acerca da sua autoridade e de suas intenções, que servem como um guia para o leitor formar juízos sobre seus relatos. A credibilidade percebida será resultado de uma intensa e permanente negociação de sentidos entre o jornalismo e seu público (LISBOA; BENETTI, 2015, p. 12).

A segunda questão sobre a qual precisamos nos debruçar, que trata das potenciais estratégias empregadas na invisibilização das fontes, também demanda atenção relacionada à credibilidade. Ao depositar sua atenção sobre os rituais estratégicos dos jornalistas, Tuchman (1993) indicou a recorrência e/ou menção às fontes como uma forma de os profissionais se preservarem de críticas e de processos judiciais. Por outro lado, numa reflexão que atenta para a invisibilização das fontes, entendemos um fator complexificador do contexto: invisibilizar fontes significaria uma anulação das estratégias de preservação dos jornalistas, de que nos falava a autora norte-americana?

Acreditamos que não. Nossa perspectiva é de que, ao se apoiar em fontes e garantir a credibilidade constituída, o produto jornalístico tem a permissão para se inscrever na ordem do discurso, seguindo amparado por procedimentos de exclusão (interdição, rejeição e vontade de verdade) dos quais falava Foucault (2009). Por isso, a invisibilização das fontes implicaria antes um deslocamento do que um esfacelamento da credibilidade da fonte especializada. Nossa hipótese é de que tais deslocamentos acontecem por meio da apropriação realizada por atores midiáticos ${ }^{3}$ sobre posicionamentos, adaptados ou não a partir do que as referidas fontes especializadas declaram, resultando numa nova construção de referenciação de credibilidade para quem consome o produto jornalístico.

No caso da opinião expressa em espaços jornalísticos, esses deslocamentos se mostram ainda mais ao considerarmos que articulistas, colunistas e comentaristas, tais como as fontes especializadas, demandam o fomento de suas posições por meio da

\footnotetext{
3 Para fins deste trabalho, consideramos atores midiáticos como indivíduos que atuam profissionalmente em espaços jornalísticos, sendo ou não jornalistas.
} 
credibilidade. No entanto, tais atores diferem em grau de especialização de cientistas e pesquisadores - o que implica a necessidade da reflexão sobre os movimentos que propiciam eventuais apropriações e, consequentemente, deslocamentos de credibilidade.

Nossa reflexão se baseia no fato de que o jornalismo precisa contar com a confiança de quem o consome. Conforme Lisboa (2012), a credibilidade se forma no contexto de uma relação e tem dependência direta da perspectiva do outro sujeito.

\section{Coronavírus na mídia: 0 Grande Debate}

Até o final da primeira quinzena de novembro de 2020, a pandemia causada pelo novo coronavírus provocou 1,3 milhão de mortes e mais de 54 milhões de casos ao redor do mundo ${ }^{4}$. Na esteira da crise sanitária, vieram também o agravamento de problemas sociais e econômicos, implicando a abordagem de temas relacionados direta ou indiretamente ao novo coronavírus em notícias, reportagens, comentários e tantos outros espaços, destacando-se entre tais temas a própria pandemia e/ou questões decorrentes de medidas adotadas em função de medidas preventivas e/ou de controle no novo coronavírus.

Além da presença no noticiário, a referida pandemia também se tornou tema de programas e/ou quadros que exploravam o debate como formato - um espaço para a manifestação das opiniões em espaços jornalísticos. Casos como o já tradicional Jornal da Cultura (exibido desde 1986 pela TV Cultura), bem como os mais recentes GloboNews Debate (no ar desde abril de 2020, no canal GloboNews) e Opinião no Ar (veiculado desde setembro de 2020 pela RedeTV!), entre outros, constam entre os exemplos em que as opiniões de comentaristas sobre assuntos que figuraram entre as notícias são postas em confronto.

Um dos espaços midiáticos que explorou a pandemia sob diferentes recortes e perspectivas foi o quadro O Grande Debate, exibido pelo canal CNN Brasil ao vivo entre segunda e sexta-feira em dois programas: a partir das $6 \mathrm{~h}$, durante o jornalístico CNN Novo Dia, e às 18h30, durante o Expresso CNN. O quadro foi escolhido para ser objeto de nossa análise por, além de se juntar à lista das iniciativas apontadas anteriormente, destacar-se em crescimento de audiência e aceitação do público. No ar desde março de 2020, mês de 
início das transmissões da CNN Brasil, foi apontado pelo canal como um de seus maiores êxitos 5 .

O quadro tem a condução de um mediador ou mediadora que apresenta o tema que será discutido por dois comentaristas, com a proposta de que estes defendam pontos de vista contrários para que, segundo afirmam os mediadores, o telespectador tenha a possibilidade de construir sua própria opinião.

O tema a ser debatido, invariavelmente, está entre as notícias veiculadas durante o programa no qual o quadro é exibido. Em todas as edições de O Grande Debate, o mediador exalta a importância do quadro, mencionando seu sucesso nos Estados Unidos e sua transposição para o Brasil. O tema e as credenciais dos comentaristas são brevemente introduzidos. Na sequência, o apresentador aborda um recorte do tema a ser debatido, solicitando a opinião dos comentaristas - que se expressam dentro de um limite de tempo e com a possibilidade de exercitar não só a réplica como a tréplica, conforme a exposição dos argumentos.

Não há duração regular entre os quadros nem publicização de tempo para a expressão de cada um dos debatedores. Para fins de nosso trabalho, e diante da pandemia provocada pelo novo coronavírus, entendemos que observar a invisibilização de fontes nos debates que versassem sobre a crise sanitária mundialmente instalada nos proporcionaria uma visão sobre como, nos debates sobre o tema, opinião e fontes científicas conviveriam. Assim, optamos por nos debruçar apenas sobre as edições que tratassem sobre a pandemia causada pelo novo coronavírus.

Até o dia 30 de julho, foram ao ar 180 debates, protagonizados por diferentes comentaristas e conduzidos por diferentes mediadores. Destes, 14 exploram temas relacionados à pandemia provocada pelo novo coronavírus, dos quais dez referem-se a acontecimentos já ocorridos no momento da veiculação dos quadros (contemplando desde questões relacionadas às medidas de controle e prevenção, bem como reflexos sociais e econômicos da pandemia), e quatro exploram propostas de ações futuras a serem ou não implementadas pelo poder público no combate à pandemia. Como quatro edições discutiam sobre possibilidades e não fatos, optamos por eliminá-las, mantendo selecionadas as

5 Cf. Forbes: em um mês, CNN disputa topo da TV paga e amplia foco em pandemia. Disponível em: https://www.cnnbrasil.com.br/nacional/2020/04/15/forbes-em-um-mes-cnndisputa-topo-da-tv-paga-e-amplia-foco-em-pandemia. Acesso em: 12 dez. 2020. 
demais para a constituição de nosso corpus de observação e análise para a verificação de ocorrência de invisibilização de fontes sobre o assunto.

\section{Metodologia}

O presente artigo caracteriza-se como um estudo essencialmente empírico e qualitativo, voltado para a observação de ocorrências em produto jornalístico, tendo seus objetivos alcançados a partir das considerações referentes às manifestações demonstradas publicamente por comentaristas em dez edições do quadro O Grande Debate.

A presente proposta demanda um olhar analítico que não esteja apenas atento às especificidades regulares características do corpus escolhido para o estudo - selecionado e atravessado por procedimentos de investigação e descrição, para que pudéssemos promover a comprovação ou refutação de nossa hipótese (BAUER; AARTS, 2002) -, mas que também exercite a percepção crítica dos aspectos que nos propomos a analisar. Por isso, segmentamos nossos esforços na combinação de estratégias divididas em duas etapas.

A primeira delas caracterizou-se pelo exame detalhado de todo o material. Foram observados os atores envolvidos em cada debate, a fim de agruparmos os participantes conforme características constitutivas de suas condições de participação. Também realizamos a detecção do tema geral e dos subtemas dentro de cada edição analisada. Entendemos que essa primeira etapa se fazia necessária por oportunizar a verificação de cenários férteis para o acionamento de fontes especializadas conforme os macro e microtemas debatidos.

Já a segunda etapa foi composta pelo levantamento das fontes mencionadas pelos comentaristas no decorrer dos debates. Nesta parte, estabelecemos os seguintes critérios a serem observados no levantamento: 1) as fontes deveriam se caracterizar como especializadas (entendidas no presente trabalho como especialistas, oficiais ou técnicas), independentemente de suas áreas de atuação; e 2) as fontes poderiam ser indivíduos, entidades ou documentos. Menções à mídia como veiculadora de situações às quais os comentaristas se referissem não seriam interpretadas como citações de uma fonte pública de informações e, portanto, não entrariam em nosso levantamento.

Nos dois momentos, a fim de sistematizarmos nossos esforços metodológicos e garantirmos uma observação detalhada dos cenários sobre os quais nos debruçamos, 
optamos pela categorização a partir de características comuns compartilhadas pelos grupos observados.

\section{Fontes acionadas $\mathrm{X}$ fontes presumidas}

Tal como explicitado anteriormente, nosso percurso metodológico foi projetado para nos permitir identificar alguns traços que possam refletir sobre a detecção do fenômeno da invisibilização das fontes especializadas na abordagem da pandemia provocada pelo novo coronavírus no quadro O Grande Debate. Detalhamos os cenários obtidos conforme as etapas indicadas para, em seguida, discutirmos o que os resultados indicam isolada e conjuntamente.

Perfis - A observação dos atores envolvidos nos debates nos permitiu a verificação dos perfis dos comentaristas, a fim de analisar quaisquer traços de especialidade em assuntos determinados a partir da apresentação feita pelos profissionais que mediaram os debates. Considerando as dez edições do quadro analisado, percebemos quatro apresentadores e sete comentaristas, conforme descrito abaixo:

Quadro 1 - Perfis dos participantes

\begin{tabular}{|c|c|c|}
\hline Posição & Nome & Perfil \\
\hline \multirow{4}{*}{ Apresentador(a) } & Reinaldo Gottino & Jornalista \\
\cline { 2 - 3 } & Monalisa Perrone & Jornalista \\
\cline { 2 - 3 } & Carol Nogueira & Jornalista \\
\cline { 2 - 3 } & Rafael Colombo & Jornalista \\
\hline \multirow{4}{*}{ Comentaristas } & Gabriela Prioli & Advogada \\
\cline { 2 - 3 } & Tomé Abduch & Empresário \\
\cline { 2 - 3 } & Caio Coppolla & Bacharel em Direito \\
\cline { 2 - 3 } & Augusto de Arruda Botelho & Advogado \\
\cline { 2 - 3 } & Thiago Anastácio & Advogado \\
\cline { 2 - 3 } & Gisele Soares & Advogada \\
\cline { 2 - 3 } & Veronica Sterman & Advogada \\
\hline
\end{tabular}

Fonte: Elaboração própria (2020). 


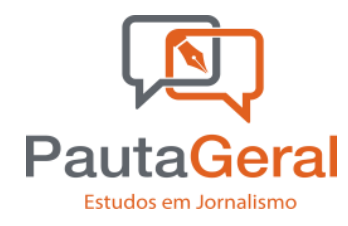

Enquanto o perfil dos mediadores dos debates é ocupado por jornalistas profissionais, que salientam durante diferentes momentos do quadro que ali estão para passar informações para o telespectador (reforçando uma pretensa separação entre jornalismo e opinião), o perfil dos comentaristas compartilha uma quase totalidade de formações em comum: com exceção de Tomé Abduch, que por formação é engenheiro civil, todos cursaram Direito. Tal especificidade sugere uma especialidade para assuntos que versem sobre a legalidade dos cenários apresentados, mas também uma dependência de fontes especializadas em outros assuntos.

Temas - Ao estabelecermos a divisão de temas explorados nas dez edições de 0 Grande Debate, percebemos que a condução das edições do quadro estipulava também microtemas para cada ocasião, indicados pelos mediadores. Abaixo, e conforme a indicação dos números que sinalizam as abordagens de macro e, respectivamente, microtemas em cada debate, apontamos o que foi observado em cada edição analisada.

Quadro 2 - Macrotemas

\begin{tabular}{|c|c|}
\hline Debate & Macrotema explorado \\
\hline 1 & Atuação do governo no combate à pandemia \\
\hline 2 & Gerenciamento da pandemia entre a população carcerária \\
\hline 3 & Isolamento vertical \\
\hline 4 & Monitoramento de aglomerações por meio do celular \\
\hline 5 & Ampliação da quarentena \\
\hline 6 & Obrigatoriedade do uso de máscaras \\
\hline 7 & Lockdown \\
\hline 8 & Antecipação de feriados para evitar aglomerações \\
\hline 9 & Indicação de uso da hidroxicloroquina \\
\hline 10 & Fonte: Elaboração propria (2020) \\
\hline
\end{tabular}

Fonte: Elaboração própria (2020).

Quadro 3 - Microtemas

Debate Microtemas explorados




\begin{tabular}{|c|c|}
\hline 1 & $\begin{array}{l}\text { Início de implementação de medidas de combate; comportamento de chefes } \\
\text { de Estado; relação entre pedidos de impeachment e crise provocada pela } \\
\text { pandemia; adequação de medidas adotadas às necessidades da população. }\end{array}$ \\
\hline 2 & $\begin{array}{l}\text { Posicionamentos do governo sobre medidas para combate à pandemia entre } \\
\text { a população carcerária; agravamento do quadro devido à superlotação das } \\
\text { cadeias; retirada de benefícios concedidos à população carcerária; suspensão } \\
\text { de visitas. }\end{array}$ \\
\hline 3 & $\begin{array}{l}\text { Opiniões sobre o isolamento vertical; divergências entre membros do governo; } \\
\text { efeitos dos posicionamentos divergentes no combate à pandemia; auxílio } \\
\text { financeiro imediato para a população. }\end{array}$ \\
\hline 4 & $\begin{array}{l}\text { Adequação da droga para o tratamento da Covid-19; corresponsabilidade entre } \\
\text { médico e paciente; omissão de resposta sobre o uso de hidroxicloroquina por } \\
\text { membro do governo; responsabilidade por indicação de uso da medicação por } \\
\text { autoridades. }\end{array}$ \\
\hline 5 & $\begin{array}{l}\text { Proteção de liberdades individuais; medidas voltadas para micro e pequenas } \\
\text { empresas; reedição da CPMF; divergências entre agentes públicos sobre a } \\
\text { pandemia. }\end{array}$ \\
\hline 6 & $\begin{array}{l}\text { Ligação possível entre medida e manobra política; potencial oportunismo em } \\
\text { posturas de ministros; liberação de fundo partidário para combate à pandemia. }\end{array}$ \\
\hline 7 & Possibilidade de realização de campanhas ou aplicação de multas. \\
\hline 8 & Viabilidade de confinamento total e seu reflexo na economia. \\
\hline 9 & Acertos e erros cometidos no estado de São Paulo. \\
\hline 10 & $\begin{array}{l}\text { Uso do termo de consentimento; autonomia do paciente; interpretação de } \\
\text { medidas governamentais sobre o medicamento; interpretação de falas de } \\
\text { autoridades. }\end{array}$ \\
\hline
\end{tabular}

Fonte: Elaboração própria (2020).

As observações acima nos permitiram estabelecer uma divisão temática a fim de ligar a exposição dos temas às fontes que deveriam ser pretensamente acionadas a partir do alinhamento entre tema e área de especialidade. Desse modo, estipulamos as seguintes categorizações de temas:

- Gerenciamento e medidas: voltados para a exploração de ações gerais implementadas por instâncias governamentais para a minimização de danos provocados pela crise sanitária. É o caso dos debates 1, 2, 3, 6, 8 e 9.

- Sanções sociais: que exploravam a possibilidade de sanções eventuais para indivíduos que desrespeitassem recomendações de prevenção e controle da crise sanitária. Encaixam-se aqui os debates 5 e 7.

- Indicações medicamentosas: que tratavam de discussões sobre a administração de drogas para a prevenção, tratamento ou cura da Covid-19. É o caso dos debates 4 e 10. 
Nossa categorização de grandes áreas temáticas, apoiada nas observações das especificidades de cada um dos quadros observados, nos permitiu elaborar um quadro de fontes presumidas: aquelas que, conforme suas áreas de especialidade ou especificidade de conteúdo (no caso de documentos), seriam acionadas pelos comentaristas a fim de justificarem ou fortalecerem a exposição de suas opiniões. Nosso entendimento de fontes presumidas para cada categoria temática indicava a pertinência de médicos, pesquisadores, cientistas, revistas científicas, documentos e/ou dados emitidos por órgãos oficiais.

Fontes acionadas - A partir do acompanhamento das falas dos comentaristas em cada um dos debates observados, listamos as fontes mencionadas sem a identificação de nomes (no caso de especialistas ou representantes de instâncias governamentais ou organizacionais). Além de menções aos casos midiaticamente veiculados e suas respectivas abordagens pelos comentaristas envolvidos, percebemos as seguintes ocorrências:

Quadro 4 - Fontes

\begin{tabular}{|c|c|}
\hline Debate & Fontes acionadas \\
\hline 1 & Organização Mundial da Saúde; governo federal; "os economistas”. \\
\hline 2 & STF, CNJ, Infopen, IDDD, TRF, TJSP. \\
\hline 3 & $\begin{array}{l}\text { Especialista em saúde pública; cientista; artigo científico; Ministério da Saúde; } \\
\text { STF; professor; presidente de empresa; "alguns especialistas"; "minha } \\
\text { experiência"; "estudos do mundo todo". }\end{array}$ \\
\hline 4 & $\begin{array}{l}\text { Representante de rede privada de hospitais; Código de Ética Médica; "minhas } \\
\text { fontes"; "estudo que será publicado". }\end{array}$ \\
\hline 5 & Constituição Federal; União Europeia; FMI; universidade; pesquisador. \\
\hline 6 & Pesquisador; médico; dados emitidos pelo estado de São Paulo. \\
\hline 7 & Lei Municipal de São Paulo. \\
\hline 8 & Infectologista; Ministério da Saúde; universidade. \\
\hline 9 & Médico; Censo Covid-19; lei; representante do governo. \\
\hline 10 & STF; Conselho Federal de Medicina; documentos legais. \\
\hline
\end{tabular}

Fonte: Elaboração própria (2020). 
O cruzamento dos dados obtidos a partir de nossas observações nos permite apontar um descompasso entre as instâncias que constituem os debates e suas propostas temáticas, em três níveis distintos: áreas de atuação dos comentaristas, áreas temáticas e fontes acionadas.

Ao mesmo tempo em que as áreas de atuação dos comentaristas os credenciam como especialistas em suas respectivas atuações profissionais, estas os tornam irremediavelmente dependentes de fontes especializadas a fim de validarem suas colocações, sob pena de tratarem sobre temas dos quais não têm conhecimento.

Por outro lado, e reforçando as condições acima mencionadas, a estipulação temática lida apenas (quando muito) tangencialmente com as possibilidades de interpretação conforme as áreas de atuação dos comentaristas. O confronto entre suas áreas de atuação e temas explorados aponta um desencontro entre assuntos e debatedores.

Ao colocarmos possibilidades de fontes presumidas (aquelas cujos conhecimentos as tornariam aptas a basearem as opiniões expostas pelos comentaristas), percebemos a divisão de espaços entre fontes do campo jurídico ou empresarial e fontes do campo médico-científico com fontes indeterminadas. Isso permite apontar a convivência entre fontes que atuam na área de discussão do tema com aquelas cuja existência não se pode confirmar e com fontes que não têm ligação com os temas discutidos em pretensa igualdade de condições. Também neste momento de nossa reflexão, percebemos a incidência de fontes que se encaixavam em características de fontes presumidas (caso de instância investida de autoridade, tais como pesquisadores, professores ou instituições), porém advindas de fora da instância médico-científica, camuflando sua inadequação por meio de credenciais de autoridade e ignorando credenciais de especificidade de área.

As fontes especializadas que deveriam ser acionadas a fim de abordar a pandemia provocada pelo novo coronavírus, por seu turno, aparecem em apenas $50 \%$ dos debates, em oposição a fontes indeterminadas em $30 \%$ dos quadros e $70 \%$ de fontes do campo jurídico ou empresarial.

\section{Considerações finais}

Uma crise sanitária de proporções mundiais traz consequências que não podem ser desconsideradas nas reflexões desenvolvidas sob quaisquer aspectos e espectros de observação. Quando tais questões permeiam os espaços jornalísticos, a atenção 
demandada para a reflexão empreendida requer, constante e crescentemente, um olhar voltado para os movimentos que resultarão nos produtos finais consumidos pelo público.

Ao nos propormos realizar um estudo sobre a invisibilização de fontes num espaço de exposição de opiniões em veículo jornalístico, escolhemos nos concentrar em uma possibilidade cuja efetivação e potencial desdobramento tem ligação com a discussão sobre credibilidade.

Neste sentido, nossos resultados apontam uma invisibilização gradual de fontes da área médico-científica em detrimento de aparição de fontes indeterminadas e/ou de outros campos: se não é possível afirmar a completa ausência de menção às primeiras, tampouco há a relação direta estabelecida entre perfis de comentaristas, temas e fontes acionadas nas edições de O Grande Debate analisadas neste trabalho.

Tais cenários percebidos em nossa pesquisa nos permitem refletir positivamente sobre a realização de um deslocamento de credibilidade refletida a partir das fontes acionadas. Neste caso, a credibilidade é estabelecida em função da exposição midiática dos atores envolvidos no debate, implicando fontes especializadas nos assuntos abordados tendo sua relevância sobrepujada em detrimento das interpretações dos comentaristas.

Neste ponto de nossa reflexão, merece especial atenção um olhar atento sobre um deslocamento secundário e consequente ao que já mencionamos: o comentarista assume, potencialmente, o lugar de fonte para quem consome o produto jornalístico em questão. Entendemos ainda que outra consequência do que percebemos em nosso trabalho é a percepção de um enfraquecimento institucionalizado de instâncias de validação direta das fontes acionadas.

Os pontos acima indicados têm, consequentemente, desdobramentos ligados às motivações e às consequências da promoção dos deslocamentos de credibilidade aos quais nos referimos anteriormente. Nomearemos esses pontos de reflexão como pontos nevrálgicos da invisibilização das fontes.

Primeiro, merece atenção o interesse que sustenta a condução de debates cujas fontes especializadas são invisibilizadas e, para entendê-lo em sua complexidade, é preciso voltarmos nosso olhar para o entorno do que analisamos. Não podemos nos esquecer que nosso objeto de análise faz parte da programação de uma emissora, até o presente momento, com menos de um ano de atuação no Brasil, em busca da fidelização de seu público. Parece-nos importante destacar um aspecto fundamental e complexo: enquanto a recorrência exclusiva às fontes médico-científicas para tratar sobre os temas relacionados 
à pandemia provocada pelo novo coronavírus implicaria uma discussão mais técnica e, portanto, mais centrada em opiniões cuja base seriam informações especializadas; a invisibilização das fontes abre espaço para um produto espetacularizado, essencialmente sustentado pela transição entre o jornalístico e o grotesco.

No espetáculo, as fontes não têm protagonismo: ficam à margem de uma construção cujo resultado proporciona um espetáculo no qual a matéria-prima jornalística por excelência (a notícia, a informação) abre espaço para o flerte com a desinformação, a exposição de fake news sob os mesmos pressupostos de validade e/ou legitimidade que informações técnico-científicas. Embora nosso primeiro impulso seja salientar a ligação dessas colocações com a preocupação envolta com o ponto da credibilidade (ainda que, desta vez, seja a do veículo jornalístico), parece-nos fundamental também apontar que essa espetacularização, como cenário da invisibilização das fontes, atua potencialmente como uma espécie de câmara de fortalecimento de discursos polarizados.

O discurso, já disse Foucault (2009), está inscrito numa ordem e, portanto, há regras, ditames que precisam ser seguidos, autorizações que precisam ser conquistadas ou conferidas e que incidem diretamente sobre o que é dito ou não dito. A invisibilização de cientistas e instituições científicas como fontes em debates cujos fundamentos são de caráter científico parece apontar para um tipo de sobreposição de ordens discursivas autorizadas pela mídia: assim como o espetáculo se impõe ao jornalístico, diferentes discursos (que refletem uma polarização político-ideológica presente atualmente na sociedade) se impõem aos dados científicos. Entendemos que tais sobreposições inspiram a necessidade de olhares cada vez mais atentos às potenciais consequências danosas de tais polarizações, como o fomento de discursos sem fundamento científico revestidos de autoridade pretensamente científica.

Todavia, em decorrência desta reflexão, surgem outros questionamentos: quais as dimensões éticas de tal deslocamento? Quais os critérios de escolha do veículo jornalístico para aqueles que ocuparão os postos de comentaristas em O Grande Debate? Qual a medida de coparticipação e responsabilidade entre o canal, os jornalistas e os comentaristas quando do tratamento de temas fora de suas especialidades? Estes são alguns dos questionamentos aos quais chegamos ao final deste trabalho, cientes de que seus resultados apontam um descompasso cujas consequências extrapolam os objetivos aqui buscados. 
Notadamente, ao nos propormos a realizar o presente trabalho, precisamos não apenas nos certificar de estabelecer parâmetros capazes de nos auxiliar em nossa jornada, como também admitir as limitações do estudo. Embora coloquemos a perspectiva de apontar os movimentos que invisibilizam fontes no mencionado quadro, entendemos que se torna potencialmente interessante empreender um estudo sobre o reflexo de instâncias anteriores à exibição do produto jornalístico e que exercem, também, significativa influência na abordagem dos temas pretendidos e escolha de comentaristas, temas e subtemas a serem abordados. Acreditamos que se faz interessante no futuro, e colocando como potenciais desdobramentos de estudos sobre invisibilização de fontes, o desenvolvimento de trabalhos nos quais sejam empreendidos esforços metodológicos de inspiração etnográfica.

\section{Referências}

ALSINA, Miquel Rodrigo. A construção da notícia. Petrópolis: Vozes, 2009.

ANTUNES, Elton; GÓES, José Cristian. A invisibilização identitária da África lusófona na Folha de S. Paulo e em O Globo. Revista Observatório, Palmas, v. 1, n. 1, p. 147-170, mai./ago., 2015.

BAUER, Martin; AARTS, Bas. A construção do corpus: um princípio para a coleta de dados qualitativos. In: BAUER, Martin; GASKELL, George (Orgs.). Pesquisa qualitativa com texto, imagem e som: um manual prático. 2. ed. Petrópolis: Vozes, 2002.

CARVALHO, Rafiza Luziani Ribeiro. Notícias falsas ou propaganda?: uma análise do estado da arte do conceito de fake news. Questões Transversais - Revista de Epistemologias da Comunicação, São Leopoldo, v. 7, n. 13, p. 21-30, jan./jun., 2019.

CHAPARRO, Manuel Carlos. Pragmática do jornalismo: buscas práticas para uma teoria da ação jornalística. São Paulo: Summus Editorial, 1994.

CHAPARRO, Manuel Carlos. Jornalismo: linguagem dos conflitos. São Paulo: Edição do autor, 2014.

COSTA, Juliana; MAIA, Kênia. Panorama dos estudos brasileiros sobre fontes jornalísticas. In: XV CONGRESO DE LA ASOCIACIÓN LATINOAMERICANA DE INVESTIGADORES DE LA COMUNICACIÓN, 2020, Medellín. Anais do XV Congreso de la Asociación Latinoamericana de Investigadores de la Comunicación. No prelo.

ERBOLATO, Mário L. Técnicas de Codificação em Jornalismo. 5. ed. São Paulo: Ática, 2008. 
FOUCAULT, Michel. A ordem do discurso. 19. ed. São Paulo: Edições Loyola, 2009.

HALL, Stuart; CHRITCHER, Chas; JEFFERSON, Tony; CLARKE, John; ROBERTS, Brian. A produção social das notícias: o mugging nos media. In: TRAQUINA, Nelson (Org.). Jornalismo: questões, teorias e estórias. Lisboa: Vega, 1993.

JORGE, Thaís de Mendonça. Notícias e fake news: uma reflexão sobre dois aspectos do mesmo fenômeno da mutação, aplicada ao jornalismo contemporâneo. Âncora: Revista Latino-americana de Jornalismo, João Pessoa, v. 4, n. 2, p. 57-73, jul./dez., 2017.

KISCHINHEVSKY, Marcelo; CHAGAS, Luan. Diversidade e pluralidade de fontes no jornalismo da Bandnews Fluminense FM. In: XXVI ENCONTRO ANNUAL DA COMPÓS, 2017, São Paulo. Anais do XXVI Encontro Annual da Compós. São Paulo: Faculdade Cásper Líbero, 2017a. p. 1-21.

KISCHINHEVSKY, Marcelo; CHAGAS, Luan. Diversidade não é igual à pluralidade: proposta de categorização de fontes no radiojornalismo. Galáxia, São Paulo, v. 1, n. 36, p. 111-124, set./dez., 2017b.

KUSCINSKY, Bernardo. Jornalismo e saúde na era neoliberal. Saúde e Sociedade, São Paulo, v. 11, n. 1, p. 95-103, jan./jul., 2002.

LAGE, Nilson. A reportagem: teoria e técnica de entrevista e pesquisa jornalística. 5. ed. Rio de Janeiro: Record, 2005.

LISBOA, Silvia Saraiva de Macedo. Jornalismo e a credibilidade percebida pelo leitor: independência, imparcialidade, honestidade, objetividade e coerência. 2012. 112p. Dissertação (Mestrado em Comunicação e Informação) - Universidade Federal do Rio Grande do Sul, Porto Alegre, 2012.

LISBOA, Silvia; BENETTI, Márcia. O jornalismo como crença verdadeira justificada. Brazilian Journalism Research, Brasília, v. 11, n. 2, p. 10-29, dez., 2015.

MAIA, Kênia; GOMES, Ana Cecília Aragão. Para pensar o fazer e a pesquisa em divulgação científica e o jornalismo científico. In: XXIX CONGRESSO BRASILEIRO DE CIÊNCIAS DA COMUNICAÇÃO, 2006, Brasília. Anais do XXIX Congresso Brasileiro de Ciências da Comunicação. Brasília: Universidade de Brasília, 2006. p. 1-14.

MELO, José Marques de. Jornalismo opinativo: gêneros opinativos no jornalismo brasileiro. 3. ed. Campos do Jordão: Mantiqueira, 2003.

MELO, José Marques de. Panorama diacrônico dos gêneros jornalísticos. In: XXXIII CONGRESSO BRASILEIRO DE CIÊNCIAS DA COMUNICAÇÃO, 2010, Caxias do Sul. Anais do XXXIII Congresso Brasileiro de Ciências da Comunicação. Caxias do Sul: Universidade de Caxias do Sul, 2010. p. 1-8.

MELO, José Marques de; ASSIS, Francisco de. Gêneros e formatos jornalísticos: um modelo classificatório. Intercom - Revista Brasileira de Ciências da Comunicação, São Paulo, v. 39, n. 1, p. 39-56, jan./abr., 2016. 
MOLOTCH, Harvey; LESTER, Marilyn. As notícias como procedimento intencional: acerca do uso estratégico de acontecimentos de rotina, acidentes e escândalos. In: TRAQUINA, Nelson (Org.). Jornalismo: questões, teorias e estórias. Lisboa: Vega, 1993.

MURIBECA, Lucas; ESTEVES, Lorena; BRITO, Rosaly. Crise política brasileira e invisibilização das cotas sociais na fanpage do Ministério da Educação na era Temer. In: VIII CONGRESSO DA ASSOCIAÇÃO BRASILEIRA DE PESQUISADORES EM COMUNICAÇÃO E POLÍTICA, 2019, Brasília. Anais do VIII Congresso da Associação Brasileira de Pesquisadores em Comunicação e Política. Brasília: Universidade de Brasília, 2019. p. 1-22.

NEVEU, Erik. Sociologia do jornalismo. São Paulo: Edições Loyola, 2006.

PENA, Felipe. Teoria do jornalismo. 3. ed. São Paulo: Contexto, 2012.

PEREIRA, Ariane; CALEFFI, Renata; ALBERTINI, Caroline. Um telejornal de homens?: invisibilização e silenciamento de mulheres no Boa Noite Paraná. In: XX CONGRESSO DE CIÊNCIAS DA COMUNICAÇÃO NA REGIÃO SUL, 2019, Porto Alegre. Anais do XX Congresso de Ciências da Comunicação na Região Sul. Porto Alegre: Centro Universitário Ritter dos Reis, 2019. p. 1-14.

PINTO, Manuel. Fontes jornalísticas: contributos para o mapeamento do campo.

Comunicação e Sociedade, Braga, v. 14 (1-2), p. 277-294, Universidade do Minho, 2000.

SCHMITZ, Aldo Antonio. Fontes de notícias: ações e estratégicas das fontes no jornalismo. Florianópolis: Combook, 2011.

TRAQUINA, Nelson. Teorias do jornalismo: porque as notícias são como são. 3. ed. Florianópolis: Insular, 2012.

TUCHMAN, Gaye. A objetividade como ritual estratégico: uma análise das noções de objectividade dos jornalistas. In: TRAQUINA, Nelson (Org.). Jornalismo: questões, teorias e estórias. Lisboa: Vega, 1993.

Submissão: 17 nov. 2020

Aceite: 14 dez. 2020 